\title{
Institutional Satisfaction and Recommendation: What Really Matters to International Students?
}

\author{
Ravichandran Ammigan ${ }^{\mathrm{a} \bowtie}$
}

\begin{abstract}
This quantitative study investigates the role of satisfaction variables as predictors of institutional recommendation for over 45,000 international students at 96 different institutions globally. Using data from the International Student Barometer, it demonstrates which aspects of the university experience are most significant on students' propensity to recommend their institution to prospective applicants. This article also discusses key implications and policy recommendations for how university administrators and international educators could enhance the international student experience and strengthen recruitment and retention strategies on their respective campuses.
\end{abstract}

Keywords: international students, international student experience, student recommendation, student satisfaction

\section{Introduction}

In an increasingly competitive global market, it is vital that institutions remain attentive to the views, perceptions, preferences, and experiences of international students, particularly in terms of improving satisfaction ratings and institutional recommendation. The decision to select a destination country or institution is generally influenced by a number of "push and pull" factors that drive international students to leave their home countries to pursue an education abroad (Banjong \& Olson, 2016). These determinants include the quality of education, tuition and living costs, scholarship opportunities, post-graduation employment options, health and safety, and learning a different language such as English, which is common in destination countries like the United States, the United Kingdom, and Australia. To that extent, some institutions and countries have strengthened their strategic approach to international recruitment as they become more aware of the importance of meeting prospective students' expectations about their institutional experience (Verbik \& Lasanowski, 2007).

\footnotetext{
${ }^{a}$ University of Delaware.

${ }^{\circledR}$ Corresponding author: rammigan@udel.edu
} 
Over the past few years, however, many institutions have prioritized the recruitment of international students as a source of revenue due to financial pressures (Choudaha \& $\mathrm{Hu}, 2016)$. In some countries, budgetary cuts and government restrictions for publicly funded institutions have increased the competition for recruiting international students who are self-funded (Luo \& Jamieson-Drake, 2013). For those countries, the ability to retain their market share is unclear due to increased competition and pressure from emerging destination countries with pro-immigration programs, better job placement opportunities, and softer visa policies. Institutions have therefore turned to more aggressive international student recruitment strategies to make up costs and meet their financial goals.

International students can significantly contribute to higher education, not only financially but also culturally in terms of facilitating the development of intercultural competencies among all students and positively impacting the institution's internationalization efforts (Urban \& Palmer, 2014). Fostering meaningful engagement of international students with the rest of the university community, integrating intercultural perspectives into classrooms, and encouraging domestic students to operate in multicultural groups and teams can enhance the student experience and complement institutional recruitment and retention strategies (Urban \& Palmer, 2014). Besides the social and cultural contributions that international students make to their institutions, they also help create jobs and add invaluable scientific innovation and technological improvements to the local community (Academic Credentials Evaluation Institute, 2017).

While internationalization is often measured by the recruitment and enrollment of international students, many institutions fail to fully integrate and engage these students with the larger university community after they have been admitted and registered on campus (Spencer-Oatey, 2018). Facilitating engagement and interactions between international and domestic students can enhance the academic, social, and cultural experience for all students. Thus, university educators and administrators must be informed of the relevant implications and policy recommendations so that adequate curricular and extracurricular resources and support services are administered to improve the experience of all students.

Stemming from an article by Ammigan and Jones (2018), this study evaluates the relationship between international student satisfaction and institutional recommendation. It supports the argument that the international student experience can be a driver for institutional recruitment and retention, and for advancing campus diversity and internationalization efforts. Having international students on campus can also serve as an indicator for developing global and intercultural competence of domestic students, faculty, and staff via interactions in the classroom and engagement in other extracurricular settings. However, for these benefits to exist, institutions must be strategic in incorporating the student experience perspective at all levels of their operations, such as their service mission, faculty engagement, organizational leadership structure, and assessment priorities, so that adequate support services and interventions can be implemented to sustain such initiatives. 


\section{Literature Review}

\section{International Students}

According to the United Nations Educational Scientific and Cultural Organisation Institute for Statistics (n.d.), internationally mobile students are students who have crossed a national or territorial border for the purpose of education and are now enrolled outside their country of origin. The Organisation for Economic Cooperation and Development (2015) expands this definition by suggesting that international students are those who are admitted by a country other than their own country of citizenship, usually under special permits or visas, for the specific educational purpose of following a particular course of study at a postsecondary institution of the receiving country. This study focuses on the experience of over 45,000 undergraduate, degree-seeking international students enrolled at institutions in Australia, the UK, and the US.

\section{The United States}

The number of international students in the US grew from 723,277 in 2010 to $1,078,822$ in 2016, indicating an increase of $49 \%$ in enrollment over just 6 years. International students contributed a total of US $\$ 36.9$ billion and supported more than 450,000 jobs in the local economy during the 2016-2017 academic year (NAFSA: Association of International Educators, 2017). Having said that, U.S. institutions enrolled 31,520 fewer new international students in 2017 over the previous year, indicating a potential loss of US\$788 million in revenue for just the first year of studies. International students are critical to the competitiveness of American higher education as they can add diverse perspectives that enrich in-classroom and on-campus experiences for all students and can contribute to advancing research, economic development, and innovation in the global economy (Choudaha, 2018). However, "the recent political turmoil which began with the Presidential elections accelerated several changes which in turn are hurting the competitiveness of U.S. higher education institutions in attracting global talent, reputation, and resources" (Choudaha, 2018).

In 2017 , over $45 \%$ of institutions of higher education in the US reported declines in the enrollment of new international students, citing the social and political climate, visa difficulties, cost of U.S. higher education, and the global competition for talent as contributing factors to this shift in numbers (Baer, 2017). While the US remains the top destination market for international students, the ability of institutions to retain their market share is unclear due to increased competition and pressure from emerging destination markets with less complex visa policies and better employment opportunities.

\section{The United Kingdom}

With the UK attracting more students from overseas than any other country besides the US, international student mobility continues to be an important initiative in the government's effort to foster engagement in higher education. While there is usually a strong focus on welcoming and teaching international students on university campuses, Ilieva, Killingley, Tsiligiris, and Peak (2016) argued that less attention is often 
geared towards the quality of education provision and assessment for these students. International students contributed $£ 20$ billion to the UK economy in 2017, making their spending a major factor in supporting local economies in addition to the tuition fees that they pay (The Higher Education Policy Institute, 2018).

The United Kingdom's vote in the referendum to leave the European Union in 2016 brought about a few challenges for British institutions. Immediately after the vote, there was a rapid decline of around 41,000 international students choosing to study in the UK (Office for National Statistics, n.d.). International educators in the UK suggest that the perceptions amongst potential international students had worsened over the past 12 months, and that government policy has had a direct negative impact on their ability to recruit international students (Hobsons, 2016). They also believe that restrictions on post-graduation employment visas, for example, had an adverse effect on international student recruitment efforts. With the level of uncertainty surrounding the impact of visa regulations, tuition fees, and employment on international student enrollment, institutions in the UK must continue to focus their attention and commitment on providing a welcoming environment and improving the experience of their students on campus.

\section{Australia}

A primary component of higher education in Australia is the cultural diversity of the student population on campus, which presents opportunities for both international and domestic students to interact with peers from different cultural, social, and linguistic backgrounds (Arkoudis et al., 2013). According to the Australian Government's Department of Education and Training (2017), there was a 13\% increase in international student enrollment from the previous year, revealing the largest increase recorded in a single year. With these unprecedented numbers, international students now make up more than a quarter of all students at certain universities. A recent analysis by the Australian Bureau of Statistics confirmed that the international student sector generated about AUS $\$ 28.6$ billion in 2017, including tuition fees and living expenses, making it the country's third-largest export behind iron ore and coal (ICEF Monitor, 2017). Economists have credited the boom to the strong reputation of Australian universities, along with a slightly weaker currency and the proximity to Asia. Others have suggested that it may be related to concerns about changes in immigration and visa policies currently affecting other countries.

However, according to the Regional Universities Network, the Australian government's recent budget cut and domestic funding freeze could significantly impact future student enrollment at universities and, in turn, increase competition for international students (Crace, 2018). With lower enrollments of domestic students, many Australian universities might turn to even more aggressive international student recruitment strategies to make up costs and meet their financial goals. Through a series of collaborative programs led by the Australian Education International (2012), universities continue to explore ways to enhance orientation programs, increase awareness of support services, and gain a better understanding of how to address the needs of international students. 


\section{International Student Satisfaction}

Student satisfaction is the student assessment of services provided by universities and colleges, which includes the quality of teaching and academic services, support facilities, physical infrastructure, and the social climate on campus (Wiers-Jenssen, Stensaker, \& Grøgaard, 2002, p. 185). Satisfaction ratings provide institutions with a sense of what students are experiencing in the various university settings and environments. An important strategic priority at many institutions of higher education has been to improve student satisfaction and experience, which is seen as a critical recruitment and retention strategy for providing a high-quality education and remaining competitive in the global student market and world rankings (Baranova, Morrison, \& Mutton, 2011; Shah \& Richardson, 2016).

In recent years, there has been a growing interest from international educators to gather and utilize international student satisfaction data as a way to influence campus change and strengthen support services for this community. Just like at the national level, where governments are assessing their quality assurance policies with regards to meeting the needs of international students, host institutions are using student feedback, obtained via benchmarking instruments, as an indicator of educational quality and a measure to improve services that lead to student success (Shah \& Richardson, 2016). Institutions that admit international students cannot expect these students to adjust to their new campus and be successful without adequate levels of support, advising, and programming services (Andrade, 2006).

A recent study by Ammigan and Jones (2018), which also uses International Student Barometer (ISB) data, found that the arrival, learning, living, and support services dimensions of the international student experience had significant impact on their overall university satisfaction. Of those four dimensions, the learning experience was the most influential. Students also indicated that their first night stay, the quality of accommodation, the quality of lectures, and services provided by their International Office were the most significant satisfaction variables within each dimension of experience.

\section{Arrival Experience}

Leaving family and friends back home to study in a foreign country can be an exhausting experience. International students are often nervous to take on this long journey that usually involves challenges such as obtaining a student visa, speaking English, finding accommodation, managing the cost of living, meeting new people, fitting into a new environment, and adjusting to a new classroom culture (Brett, 2013). The experience of arrival to campus can therefore be critical for new international students to get started on a positive note and navigate all the remaining challenges that await them. Universities must be intentional in setting up adequate support services, such as orientation programs, airport pick up, and social activities, that can ease the transition to campus and meet the expectations of incoming students.

Preparing international students on what to expect even before they reach their university can help them transition smoothly and settle quickly into their new environment. "Sensitization" to campus resources early upon arrival can be very 
important in reducing challenges faced by students-by assisting them in adapting to campus and by providing support for improving their academic performance (Banjong, 2015). Pre-arrival information and guidance on the visa application process, transportation, housing, health insurance, class registration, and other key issues can be made readily accessible in students' admissions packets and through existing online and social media platforms.

\section{Learning Experience}

Integrating international students in the classroom through quality education and teaching expertise has become a priority at many institutions (Hellsten \& Prescott, 2004). Evidence suggests that international students are generally more academically engaged in their first year than domestic students, and at the same time, shows that faculty assumptions about international student behavior in the classroom are often incorrect (Andrade, 2006). The classroom culture, which includes interstudent interactions such as group work and participation, level of formality or informality required when communicating with faculty, and other language and communication barriers, is one of the biggest challenges faced by international students (Sarkodie-Mensah, 1998). It is therefore important for institutions to actively assess and address the different types and levels of support required by international students in their academic environment.

Shah and Richardson (2016) found that an increased focus on course design, curriculum content and learning resources, teaching methods, student placements or practicums, engagement with staff, technology, and assessments were key factors in supporting the international student learning experience. Hellsten and Prescott (2004) suggested that an inclusive teaching philosophy is essential in serving the academic needs of international students in the classroom. This is coupled with the need to increase cultural awareness in pedagogy and teaching methods, as well as the necessity to create opportunities for discussions between international students and faculty or academic staff in university learning settings. Montgomery (2010) suggested through a constructivist approach that, while the many influences on the international student experience are complex in nature, the social context of learning can improve the quality of learning experiences. The skills and competencies that students develop as a result of their learning experiences in a new social and academic environment can help them become global citizens. A supportive campus network and community of international students can serve as a basis for developing meaningful cross-cultural experiences for everyone at that institution.

\section{Living Experience}

While the benefits of moving to another country to study are abundant academically, culturally, and socially, it can also prove to be a very expensive option for many students. It is therefore not surprising that international students and their families have high hopes and expectations when it comes to the living environment that institutions provide for students, including affordable housing, transportation options, dining services, safety and security, internet and technology, and opportunities to meet other students locally (Brett, 2013). 
Life outside the classroom can be a critical aspect of any international student's experience on campus. Culture shock, social isolation, expectations from family and home, cross-cultural relationships, financial difficulties, immigration regulations, housing, and employment options are examples of issues that can lead to added stress, anxiety, and depression (Sarkodie-Mensah, 1998). Arthur (2017) suggested two important factors that can assist international students with their social adjustment and transition to campus and at the same time reduce loneliness and homesickness: (1) the availability of counselors to discuss issues surrounding perceived intercultural adjustment and culture shock, networking skills, navigating relationships, and peer support, (2) the opportunity to establish friendships and foster cross-cultural engagement with local students through volunteer and student leadership programs, registered student organizations, and social activities in residential halls and other locations on campus.

\section{Support Services Experience}

Besides the classroom experience, international students also have expectations about how campus life will add value to their university experience. The support provided outside of the academic setting, such as tutoring, study skills, careers advice, counseling services, library resources, and physical space for learning, can be equally important to maintain academic satisfaction and success on campus (Sarkodie-Mensah, 1998). Roberts and Dunworth (2012) argued that student support services can contribute directly to international student satisfaction and that service providers must be more aligned with students' expectations and needs if they are to increase satisfaction levels. The authors found that, while support services may be abundant and welcomed, international students were not always aware of the full range of services offered and did not understand what the services were specifically for or how to access them.

Hanassab and Tidwell's (2002) supported the argument that international students can have a significant impact at institutions of higher education and that it is critical to regularly access students' experiences. Because of the unique needs often experienced by new international students, such as financial stability, adapting to local customs, establishing a network of support, and overcoming language barriers, university support services must be equipped to address emotional or psychological concerns possibly caused by adjustment issues. The authors reiterated the importance for institutions to develop adequate support services and to have a sufficient amount of expertise and staffing to handle new challenges faced by this community.

\section{Institutional Choice and Recommendation}

The concept of institutional recommendation is closely related to satisfaction in the sense that satisfied students are more likely to recommend their institution to future students (Mavondo, Tsarenko, \& Gabbott, 2004). There is also a higher probability that these students would return to enroll in higher degrees, become valued alumni, and offer job placement opportunities to current students. The decision of prospective international students to select an institution is based on a number of factors, such as institutional reputation, safety and security, university environment, quality of life, and 
visa requirements. However, the recommendation from family, friends, and acquaintances can be one of the most influential motives in their decision-making process (Mavondo, Tsarenko, \& Gabbott, 2004).

Cubillo, Sánchez, and Cerviño (2006) proposed five main factors that can influence prospective international students' institutional choice: (1) personal factors including career prospects, making international contacts, improving language skills, and recommendation from family, friends and professors; (2) the host country's image including cost of living, visa procedures, social aspects, and opportunities to work; (3) the reputation of the city, such as safety and security, social facilities, and the local environment; (4) the status of the institution in terms of ranking, campus atmosphere, research opportunities, experience and expertise of faculty, quality of education, and academic resources; and (5) the evaluation of the program of study, including tuition cost, variety and quality of courses, and recognition by future employers.

Brett (2013) found that teaching quality, personal safety, and the perceived reputation of the institution and education system were the most important factors influencing students' decisions on where to study. Other factors include university websites and an informal network of friends, parents, current students, and alumni. In addition, a recent report showed that course offerings were the main driver of student decisions on institution and location, with the expectation that the chosen course of study would lead to career prospects (QS Enrolment Solutions, 2018). Reviews and marketing materials showcasing the quality of teaching and the experience of academic staff was the second most influential factor in choosing an institution. The report also showed that prospective students were most concerned about the cost of living and the ability to afford the tuition fees. Having a relative or friend in a destination country and receiving information about local culture and customs can help reduce concerns and worries about going to study abroad and impact students' choice of a particular location. Campus safety and a welcoming environment were also important factors in international students' institutional and destination choice.

A survey-based study by Nicholls (2018) demonstrated that international students appear to first choose the country and institution in which they want to study, rather than the actual location of the university within that country. Also important to the respondents in this study was the quality of education, the reputation and ranking of the institution and academic department, safety and security, and the cost and affordability of the program of study. Alfattal (2017) found that the factors influencing students' choice of an institution as their study destination varied between international and local students. Seven choice factors were identified as driving preference differently for international students than for domestic students, namely on-campus housing, recommendation from family, academic reputation, the reputation of faculty, participation in college sports, printed material or video, and need-based financial support.

\section{Method}

The purpose of this study is to investigate the relationship between international student satisfaction and institutional recommendation. Precisely, it examines associations between different aspects of the arrival, learning, living, and support service environments 
and students' prospect of recommending their current institution to future applicants. Using multiple linear regression analyses, 80 satisfaction variables were regressed against institutional recommendation as the main dependent variable in this study.

\section{Instrument}

The ISB was used in this study to measure the degree of satisfaction and recommendation of international students. The instrument, which is considered the most widely used benchmarking tool for tracking the international student experience globally, consists of 256 close- and open-ended questions. Since its inception in 2005, the ISB has gathered feedback from more than 3 million students in over 1,400 institutions across 33 different countries (i-graduate, n.d.). It has been periodically tested for validity and reliability and refined over 14 cycles as the industry standard for measuring international student satisfaction (Brett, 2013). The online survey, administered by i-graduate, uses a 4-point Likert scale to measure satisfaction, where $1=$ very dissatisfied, $2=$ dissatisfied, $3=$ satisfied, and $4=$ very satisfied, and a 5-point Likert scale for institutional recommendation, where $1=$ actively discourage, $2=$ discourage, $3=$ neither encourage or discourage, $4=$ encourage, and $5=$ actively encourage. Satisfaction items were organized in four main sections: (1) the arrival section (11 variables), which assessed students' first impressions and experiences upon arrival to campus, (2) the learning section (27 variables), which explored students' academic environment and the aspects of teaching, studies, and facilities, (3) the living section (24 variables), comprised of questions around student accommodation, social, and day-to-day life experiences, and (4) the support services section (17 variables), which focused on services provided by university departments, such as the international office, finance department, career services, health and counseling centers, and campus eating options. The Cronbach's alpha reliability coefficient for the arrival $(\alpha=.91)$, living ( $\alpha=$ $.96)$, learning $(\alpha=.96)$, and support services $(\alpha=.98)$ variables indicated a high level of internal consistency of the satisfaction scales.

\section{Participants}

There were 45,701 international undergraduate students from 96 institutions in Australia, the UK, and the US in this study. Over $46 \%$ of student respondents $(n=21,443)$ were from the UK, $46.2 \%$ ( $n=21,117)$ were from Australia, and $6.9 \%(n=3,141)$ were from the US. Students held 204 different nationalities from countries, nation-states, and sovereign territories around the world, with $18.5 \%$ from China, $8.4 \%$ from Malaysia, and $4.1 \%$ from US. Approximately $90 \%$ of all participants were 25 years old or younger; $58.1 \%$ were female, $41.8 \%$ were male, and $0.1 \%$ identified themselves as transgender female-to-male, nonbinary/gender fluid/genderqueer, or indeterminate/intersex/unspecified. International students in this study represented 23 different disciplines at the time they took the survey. A majority of them were studying business and administrative studies (22.5\%). Over $37 \%$ of respondents stated that they were studying in a year other than their first or last year. 


\section{Procedure}

Respondents were invited by email to complete the online ISB survey in the fall 2016 semester. De-identified responses were made available by i-graduate to ensure confidentiality of the information. The author used IBM's SPSS software to run inferential analyses on the pre-existing data. Institutional Review Board approval for research on human subjects was granted by the University of Delaware for this study.

\section{Findings}

\section{Institutional Satisfaction and Recommendation}

A multiple linear regression model tested whether international students' satisfaction with their overall institutional experience, as well as with each dimension of experience (arrival, learning, living, and support services), influenced institutional recommendation. The analysis indicated that each of the four independent variables were statistically significant on the dependent variable ( $p<.001, t>1.96$; see Table 1$)$. It was found that international students' overall satisfaction with their institution $(\beta=.197, p<.001)$ positively influenced their recommendation to future applicants. Of the four dimensions of experience, "overall satisfaction with learning" impacted recommendation the most $(\beta=.233, p<.001)$, followed by "overall satisfaction with support services" $(\beta=.126, p<.001)$, and "overall satisfaction with arrival" $(\beta=.124, p<.001)$. "Overall satisfaction with living" $(\beta=.109$, $p<.001$ ) had the least influence on student recommendation.

Table 1. Impact of overall satisfaction on institutional recommendation

\begin{tabular}{lcc}
\hline \multicolumn{1}{c}{ Satisfaction variables } & $\beta$ & $t$ \\
\hline Overall satisfaction with institution* $^{*}$ & 0.197 & 19.733 \\
Overall satisfaction with arrival* $^{*}$ & 0.124 & 11.261 \\
Overall satisfaction with learning* $^{*}$ & 0.233 & 20.281 \\
Overall satisfaction with living* $^{*}$ & 0.109 & 10.039 \\
Overall satisfaction with support services* & 0.126 & 9.941 \\
\hline
\end{tabular}

Note. ${ }^{*} p<.001$.

\section{Satisfaction Variables and Recommendation}

Table 2 shows the predictive value of the various aspects of student satisfaction in each dimension of experience on students' institutional recommendation. The arrival variables that impacted institutional recommendation were the "accommodation office" ( $\beta=.184$, $p<.05)$ and "social activities" $(\beta=.129, p<.05)$. There were a number of learning variables that were significant on recommendation, namely "studying with people across cultures" $(\beta=.068, p<.001)$, "organization of course" $(\beta=.069, p<.001)$, "leading to a good job" ( $\beta=.064, p<.001)$, and "opportunities for work experience" ( $\beta=.052$, $p<.001)$. "Academic staff command of English" $(\beta=-.051, p<.001)$ was found to negatively influence institutional recommendation for international students. The most 
significant variables of the living dimension were "making friends with others from this country" ( $\beta=.124, p<.001$ ), "networking" ( $\beta=.089, p<.001$ ), and "quality of external campus environment" $(\beta=.097, p<.001)$. No Support Services variables were found to be significant on institutional recommendation.

Table 2. Impact of satisfaction variables on institutional recommendation

\begin{tabular}{|c|c|c|}
\hline Satisfaction variables & $\beta$ & $t$ \\
\hline \multicolumn{3}{|l|}{ Arrival variables } \\
\hline Accommodation office** & 0.184 & 3.242 \\
\hline Social activities** & 0.129 & 2.143 \\
\hline \multicolumn{3}{|l|}{ Learning variables } \\
\hline Studying with people across cultures* & 0.06 & 4.812 \\
\hline Organization of course* & 0.069 & 4.627 \\
\hline Leading to a good job* & 0.064 & 4.229 \\
\hline Opportunities for work experience* & 0.052 & 4.037 \\
\hline Teaching ability of lecturers* & 0.062 & 3.888 \\
\hline Academic content* & 0.061 & 3.874 \\
\hline Quality of lectures* & 0.061 & 3.700 \\
\hline Career guidance from academic staff** & 0.036 & 2.526 \\
\hline Access to academic staff** & 0.037 & 2.524 \\
\hline Improve my English language skills** & 0.037 & 2.488 \\
\hline Physical library facilities** & 0.037 & 2.451 \\
\hline Academic staff command of English* & -0.051 & -3.91 \\
\hline \multicolumn{3}{|l|}{ Living variables } \\
\hline Making friends from this country* & 0.124 & 6.392 \\
\hline Networking* & 0.089 & 4.086 \\
\hline Quality of the external campus environment* & 0.097 & 3.616 \\
\hline Immigration and visa advice ${ }^{* *}$ & 0.065 & 3.182 \\
\hline Transport links** & 0.063 & 2.753 \\
\hline Availability of financial support** & 0.043 & 2.414 \\
\hline \multicolumn{3}{|l|}{ Support Services variables } \\
\hline None & - & - \\
\hline
\end{tabular}

Note. ${ }^{*} p<.001 ; * *<.05$.

\section{Satisfaction Variables and Overall University Experience}

While the previous findings looked at the satisfaction predictors for institutional recommendation, this section used regression models to demonstrate which variables, specific to the arrival, learning, living, and support service environments, predicted overall institutional experience (see Table 3). Results indicate that only two arrival variables, experience with the "finance department" $(\beta=.137, p<.001)$ and "accommodation 
office" ( $\beta=.01, p<.05$ ), had significant impact on students' overall satisfaction with their institution. Some of the learning aspects of satisfaction that had significant impact on students' overall institutional satisfaction were "quality of lectures" ( $\beta=.085, p<.001)$, "expertise of lecturers" ( $\beta=.074, p<.001)$, "studying with people from other cultures" $(\beta$ $=.053, p<.001)$, and "organization of course" $(\beta=.055, p<.001)$. The living variables with the most significant influence on students' overall institutional satisfaction were found to be "access to suitable accommodation" ( $\beta=.074, p<.001$ ), "quality of external campus environment" ( $\beta=.066, p<.05)$, and "experience local culture" $(\beta=.005, p<.05)$. "Cost of accommodation" ( $\beta=-.036, p<.05)$ was negatively associated with the overall institutional experience of international students. Understandably so, as costs went up, satisfaction would go down. Similar to the findings for institutional recommendation, no support services variables were found to influence institutional satisfaction.

Table 3. Impact of satisfaction variables and overall experience

\begin{tabular}{|c|c|c|}
\hline Satisfaction variables & $\beta$ & $t$ \\
\hline \multicolumn{3}{|l|}{ Arrival variables } \\
\hline Finance department* & 1.137 & 2.173 \\
\hline Accommodation office** & 0.1 & 1.702 \\
\hline \multicolumn{3}{|l|}{ Learning variables } \\
\hline Quality of lectures* & 0.085 & 6.934 \\
\hline Expertise of lecturers* & 0.074 & 5.847 \\
\hline Studying with people from other cultures* & 0.053 & 4.978 \\
\hline Organization of course* & 0.055 & 4.878 \\
\hline Academic content* & 0.05 & 4.191 \\
\hline Leading to a good job* & 0.046 & 4.001 \\
\hline Improve English language skills** & 0.026 & 2.35 \\
\hline Access to academic staff** & 0.026 & 2.307 \\
\hline Physical library facilities** & 0.023 & 2.069 \\
\hline \multicolumn{3}{|l|}{ Living variables } \\
\hline Access to suitable accommodation* & 0.074 & 4.225 \\
\hline Quality of external campus environment** & 0.066 & 3.352 \\
\hline Experience local culture ${ }^{* *}$ & 0.05 & 3.051 \\
\hline Cost of living** & 0.04 & 2.734 \\
\hline Social facilities** & 0.051 & 2.669 \\
\hline Eco-friendliness attitude** & 0.039 & 2.121 \\
\hline Social activities** & 0.038 & 2.071 \\
\hline Making friends from this country** & 0.029 & 2.015 \\
\hline Cost of accommodation** & -0.036 & -2.603 \\
\hline \multicolumn{3}{|l|}{ Support Services variables } \\
\hline None & - & - \\
\hline
\end{tabular}


Note. ${ }^{*} p<.001 ; * *<.05$.

\section{Discussion}

\section{Factors Influencing Institutional Recommendation}

Findings from this study clearly show that the overall institutional experience of international students influence how they recommend their current university to future applicants. There was a strong positive association between these two variables, indicating that the more satisfied students were, the more likely they were to encourage future applicants to apply to their institution. Results also revealed that each dimension of satisfaction (arrival, learning, living, and support services) positively influenced recommendation, suggesting that the experiences of international students within these university environments were key in their recommendation to other students. The learning experience, particularly with respect to curriculum design and teaching, was found to be the most impactful, supporting studies by Shah and Richardson (2016) and Hellsten and Prescott (2004).

When the different aspects of satisfaction were examined more closely (within each dimension), several variables stood out in terms of their impact on institutional recommendation. It is perhaps not surprising to find that students' experiences with their university's accommodation office and their involvement in social activities were the most significant of the arrival variables. New international students often find it challenging to settle into their new residential environment and meet new people upon arrival to campus (Brett, 2013).

From a learning perspective, international students indicated that a multicultural classroom environment was the most important factor in their institutional recommendation to others. The structure in which their program of study and course was organized, as well as the opportunity to find employment, were also highly significant for recommendation. This signals the importance of the classroom setting and course design to students, just as much as the ability to find a good job after graduation. The academic staff command of English was found to be negatively associated with institutional recommendation, which could be an indication that students who are not native English speakers might struggle to cope with advanced vocabulary and language used by staff.

Making friends with local students was the most influential living variable on recommendation. This finding is not unexpected for the many institutions who are actively establishing programs and support services to engage international students on campus and help them develop friendships with domestic students (Arkoudis et al., 2013; Montgomery, 2010). This study, however, validates the importance of this variable from an institutional recommendation standpoint, which has potential implications for administrators and recruitment professionals.

Another interesting finding revolved around support services for international students. While no specific support variables significantly impacted recommendation, overall experience with support services was found to positively influence this dependent variable. This corresponds with the Ammigan and Jones' (2018) study, which suggested that institutions must consider placing greater emphasis on support services that enhance 
student satisfaction in the academic setting, sustained by a collaborative service model between academic departments and support units.

\section{Satisfaction Versus Recommendation}

Several variables within each dimension of experience were found to impact both institutional recommendation and overall satisfaction for international students. Table 4 indicates which of these variables were common across both dependent variables, stressing the importance of resources and support services around these aspects of experience.

Table 4. Variables impacting both recommendation and overall satisfaction

\begin{tabular}{llll}
\hline \multicolumn{1}{c}{ Recommendation } & \multicolumn{3}{c}{ Overall Satisfaction } \\
\hline Satisfaction variables & $t$ & Satisfaction variables & $t$ \\
Making friends (local)* & 6.39 & Quality of lectures* & 6.93 \\
Studying across cultures* & 4.81 & Expertise of lecturers & 5.84 \\
Organization of course* $^{*}$ & 4.62 & Studying across cultures* & 4.97 \\
Leading to a good job* & 4.22 & Organization of course* & 4.87 \\
Networking & 4.08 & Suitable accommodation & 4.22 \\
Opportunities for work & 4.03 & Academic content* & 4.19 \\
Academic staff English & -3.91 & Leading to a good job* & 4.00 \\
Teaching ability of lecturers & 3.88 & Quality of external campus* & 3.35 \\
Academic content* & 3.87 & Experience local culture & 3.05 \\
Quality of lectures* & 3.70 & Cost of living & 2.73 \\
Quality of external campus* & 3.61 & Social facilities & 2.66 \\
Accommodation Office* & 3.24 & Cost of accommodation & -2.60 \\
Immigration/visa advice & 3.18 & Improve English skills* & 2.35 \\
Transport links & 2.75 & Access to academic staff* & 2.30 \\
Career guidance & 2.52 & Finance department & 2.17 \\
Access to academic staff* & 2.52 & Eco-friendliness attitude & 2.12 \\
Improve my English skills* & 2.48 & Social activities & 2.07 \\
Physical library* & 2.45 & Physical library* & 2.06 \\
Financial support & 2.41 & Making friends (local)* & 2.01 \\
Social activities & 2.14 & Accommodation Office* & 1.70 \\
\hline
\end{tabular}

Note. ${ }^{*}$ Common variables across recommendation and overall satisfaction

There were 11 satisfaction variables that influenced both institutional recommendation and overall satisfaction, namely academic content, access to academic staff, accommodation office, improve English language skills, leading to a good job, making friends from this country, organization of course, physical library facilities, quality of external campus, quality of lectures, and studying with people from other cultures. While making friends from this country was the most significant variable on institutional recommendation, quality of 
lectures was most influential on overall satisfaction with the university. Studying with people across cultures and the organization of course were highly influential on both dependent variables.

Conversely, the unique predictors that influenced recommendation the most were networking, opportunities for work, and academic staff command of English. Expertise of lecturers, suitable accommodation, and experience local culture were the most significant variables on overall satisfaction.

\section{Implications for International Educators}

The results of this study have strong recruitment and retention implications for a number of departments and student service units across campus. Beyond working collaboratively to ensure a positive experience for all students, it would be strategic, for instance, for an institution's admissions office to work closely with their support units and alumni relations offices in identifying ways to include current international students, registered student organizations, and alums in their recruitment efforts overseas. In this context, it is important that institutions capitalize on their existing campus support services and resources as they create strategic and collaborative engagement opportunities, both in and out of the classroom. Staff from student affairs, residence life and housing, dining services, the orientation office, career services, counseling centers, transportation services, academic departments, etc., must work together to support the positive experiences of students as well as the educational mission of the institution as a global community.

\section{Arrival}

It is vital that new and incoming international students feel supported right from the moment they get to campus with services such as airport pick up and transportation, orientation programs, and other welcoming events. Assistance with first night accommodation, setting up a bank account, and financial issues and inquiries can also be key in students' first impressions of their campus. Institutions must remain intentional at creating a sense of belonging for international students through year-round programming and outreach initiatives.

Preparing international students on what to expect before they even reach their institution can also help them transition smoothly and settle quickly into their new environment. Pre-arrival information on the visa application process, transportation, housing, health insurance, class registration, and other key issues can be made readily accessible in their admissions packets and through existing online and social media platforms. It is also common for some institutions to host pre-departure orientation programs overseas even before students travel to their university. Upon arrival to campus, hybrid orientation programs with other student services units can further assist and guide international students towards a positive and successful experience. Academic advisors should be encouraged to discuss courses being offered in more detail, including class size, organization, and level of difficulty, so that students can choose a more balanced schedule prior to the start of their first semester. Working closely with academic services 
throughout the semester to pinpoint common challenges and address them through refined programming and initiatives can also serve as a proactive approach to supporting students at the beginning of their studies.

\section{Learning}

The academic setting, in the form of in-class teaching, studies, and facilities, must remain central to international students' university experience. This includes the academic and pedagogic quality of teaching, expertise of faculty and academic staff, physical infrastructure of classrooms and labs, technology, academic support services, and the social climate within the learning environment. From a marketing and recruitment perspective, administrators must be aware of the impact that learning might have on the propensity to recommend their institution to others and, in turn, be intentional at showcasing relevant academic experiences, achievements, stories, and rankings to prospective students.

With the increasing number of international students in classrooms, faculty and academic staff must also be encouraged to design courses that are conducive for learners across cultures and from different systems of education. This might include adjusting teaching and communication methods to facilitate the academic relationship between international students and faculty. There could also be an implication for how universities recruit, train, and retain qualified faculty and teaching assistants that can promote the quality of learning and academic success. Institutions must look at career planning and development for international students not only as a subsidiary support service but also with a focus on having it integrated into the curricular and classroom experience.

\section{Living}

This study confirms the need for institutions to develop opportunities for engagement and involvement between international and domestic students. These initiatives must accompany both curricular and extracurricular programs and occur in social settings inside and outside of the classroom. In addition to meeting the needs of students, creating global engagement programs such as weekly coffee hours, ice cream socials, leadership and volunteer programs, film and book clubs, conversation partners, and buddy programs can foster campus-wide collaborations in support of campus internationalization.

Another aspect of the living experience to point out is the accommodation for international students. Particularly, receiving support from the accommodation office and accessing suitable housing had a significant impact on students' overall university experience and recommendation. The cost of accommodation had a negative association with overall satisfaction, which is perhaps an expected finding. While there are many factors such as personal preferences and cost of living that could affect cost, it might be tactful for institutions to be transparent about living expenses and ensure that incoming students have a realistic expectation about accommodation costs right from the beginning of their studies.

Making friends with students from other countries was found to be the most influential living variable on institutional recommendation. It might therefore be worthwhile for institutions to introduce initiatives, such as a buddy program, networking opportunities, 
and social and cultural events, that can assist with student integration and engagement upon arrival to campus.

\section{Support Services}

Students' overall experience with their university's support services significantly impacted recommendation. This suggests the need for support offices to regularly assess student needs and adjust services in order to meet their expectations and demands, ranging from pre-arrival to graduation. Institutions must also remain strategic in how they develop and host programs and services collaboratively with other campus units such as Residence Life and Housing, Career Services, and the Counseling Center. With learning as the most influential variable on institutional recommendation, it is essential that institutions put greater emphasis on support services that enhance the academic experience and success of international students.

International student support offices can vary in organizational structure and range of services but most exist to provide assistance to international students in their educational and cultural transition to campus. These types of services provided often include orientation programs, immigration advising, assistance with academic and employment issues, and social and cultural programming. Despite recent changes in immigration policies and compliance standards, recurring safety and security concerns, and increased political instability across nations worldwide, support offices have direct access to the international community and can play an important role in furthering intercultural engagement for all at the university.

However, a point of consideration for administrators is that all too often, staff in international student support offices have to devote the majority of their time to administering government regulations and maintaining compliance with visa requirements (Briggs \& Ammigan, 2017). University administrators must adequately provide resources to such offices so they can lead programming initiatives that contribute to the broader campus internationalization efforts of their institution.

\section{Conclusions}

In addition to the various implications discussed above, findings from this study offer a few considerations to administrators and policy makers for adjusting or introducing new institutional strategies, practices, and interventions that support the international student experience. These recommendations, which introduce a basis for further discussion and study, include the following:

- Strategic reinvestment-Incorporate or reinvest resources into the student experience at all levels of operations, such as the service mission, faculty engagement, organizational leadership structure, and assessment priorities, so that adequate services and resources can be implemented to support student initiatives.

- Partnerships and collaborations-Collaborate on initiatives to reach a wider audience, adopt a cohesive, cross-departmental plan with student affairs, academic units, and other service units on campus, and remain intentional at involving a variety of campus and community stakeholders in international programming. 
- Programming and outreach-Implement culturally sensitive programming and interventions that support international students during times of high stress to help them with their academic, social and cultural adjustment to campus.

- Holistic communication-Establish a strategic communications plan and promotional campaigns to effectively reach, liaise, and optimize engagement among international students.

- Training and development-Build intercultural competence among faculty, staff, and students, aimed at understanding the experience of international students and improving views of campus services for that community.

- Assessment and benchmarking-Regularly assess the experience of international students, through assessment tools developed in-house or by external providers, to ensure quality in the assistance provided in both academic and non-academic settings.

While this empirical study investigated a large sample of students, it also had a few limitations. As with all self-report surveys, responses from the ISB may reflect response bias from participants. Additionally, this study only evaluated undergraduate, degreeseeking students and did not control for institutional type, which may influence student fit. Future research should also consider the experience of students at the graduate and nondegree levels, and possibly expand the scope to more participating institutions in emerging and non-English--speaking markets globally.

\section{References}

Alfattal, E. (2017). International students' college choice is different! International Journal of Educational Management, 31(7), 930-943.

Ammigan, R. \& Jones, E. (2018). Improving the student experience: Learning from a comparative study of international student satisfaction. Journal of Studies in International Education, 22(4), 283-301.

Andrade, M. S. (2006). International students in English-speaking universities: Adjustment factors. Journal of Research in International Education, 5(2), 131-154.

Arkoudis, S., Watty, K., Baik, C., Yu, X., Borland, H., Chang, S., \& Pearce, A. (2013). Finding common ground: Enhancing interaction between domestic and international students in higher education. Teaching in Higher Education, 18(3), 222-235.

Arthur, N. (2017). Supporting international students through strengthening their social resources. Studies in Higher Education, 42(5), 887-894.

Baer, J. (2017). Fall 2017 international student enrollment hot topics survey. Institute of International, New York.

Banjong, D. N. (2015). International students' enhanced academic performance: Effects of campus resources. Journal of International Students, 132(1), 132-142.

Banjong, D. N. \& Olson, M. R. (2016). Issues and trends of international students in the United States. International Journal of Education, 4(1), 1-14.

Baranova, P., Morrison, S., \& Mutton, J. (2011). Enhancing the student experience through service design: The University of Derby approach. volume 15. 
Brett, K. J. (2013). Making the most of your International Student Barometer data: A guide to good practice.

Briggs, P. \& Ammigan, R. (2017). A collaborative programming and outreach model for international student support offices. Journal of International Students, 7(4), 1080-1095.

Choudaha, R. (2018). A third wave of international student mobility: Global competitiveness and American higher education. in Higher Education. Retrieved fromhttps://cshe. berkeley.edu/publications/third-wave-international-student-mobility-global-competi tiveness-and-american-higher.

Choudaha, R. \& Hu, D. (2016). Higher education must go beyond recruitment and immigration compliance of international students.

Crace, A. (2018). Australia: HE funding freeze will spark competition. The Pie News.

Hanassab, S. \& Tidwell, R. (2002). International students in higher education: Identification of needs and implications for policy and practice. Journal of Studies in International Education, 6(4), 305-322.

Hellsten, M. \& Prescott, A. (2004). Learning at university: The international student experience. International Education Journal, 5(3), 344-351.

Hobsons (2016). International students are essential to UK higher education: The benefits of international students to UK universities and the impact of government policy on international student recruitment.

Ilieva, J., Killingley, P., Tsiligiris, V., \& Peak, M. (2016). The shape of global higher education. British, London.

Institute, A. C. E. (2017). What is the future of international students in the U.S.?

International, A. E. (2012). Enhancing the international student experience. Australian, Canberra.

J, M. C., J, S., \& J, C. (2006). International students' decision-making process. International Journal of Educational Management, 20(2), 101-115.

Luo, J. \& Jamieson-Drake, D. (2013). Examining the educational benefits of interacting with international students. Journal of International Students, 3(2), 85-101.

Mavondo, F. T., Tsarenko, Y., \& Gabbott, M. (2004). International and local student satisfaction: Resources and capabilities perspective. Journal of Marketing for Higher Education, 14(1), 41-16.

Monitor, I. C. E. F. (2017). Australian education exports approaching AUS\$29 billion.

Montgomery, C. (2010). Understanding the international student experience. American College Personnel Association.

((n.d). International Student Barometer.

Nicholls, S. (2018). Influences on international student choice of study destination: Evidence from the United States. Journal of International Students, 8(2), 597-622.

Roberts, P. \& Dunworth, K. (2012). Staff and student perceptions of support services for international students in higher education: A case study. Journal of Higher Education Policy and Management, 34(5), 517-528.

Sarkodie-Mensah, K. (1998). International students in the U.S.: Trends, cultural adjustments, and solutions for a better experience. Journal of Education for Library and Information Science, 39(3), 214-222. 
Shah, M. \& Richardson, J. T. E. (2016). Is the enhancement of student experience a strategic priority in Australian universities? Higher Education Research and Development, 35(2), 352-364.

Solutions, Q. S. E. (2018). Harnessing opportunities in global higher education.

Spencer-Oatey, H. (2018). New approaches to internationalisation in higher education.

Urban, E. L. \& Palmer, L. B. (2014). International students as a resource for internationalization of higher education. Journal of Studies in International Education, 18(4), 305-324.

Verbik, L. \& Lasanowski, V. (2007). International student mobility: Patterns and trends. The Observatory on Borderless Higher Education, 44, 1-21.

Wiers-Jenssen, J., Stensaker, B., \& gaard, J. B. G. (2002). Student satisfaction: Towards an empirical deconstruction of the concept. volume 8.

\section{Author biography}

Ravichandran Ammigan Ravichandran Ammigan, Ph.D., is Executive Director of the Office for International Students and Scholars at the University of Delaware, USA. 